Supplement of Atmos. Chem. Phys., 16, 11107-11124, 2016

http://www.atmos-chem-phys.net/16/11107/2016/

doi:10.5194/acp-16-11107-2016-supplement

(C) Author(s) 2016. CC Attribution 3.0 License.

(c) (i)

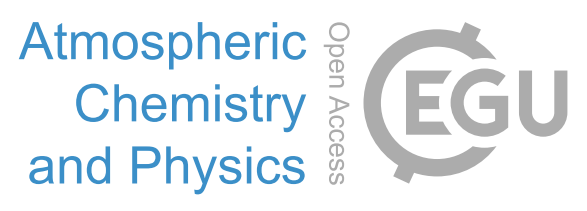

Supplement of

\title{
Effects of 20-100 nm particles on liquid clouds in the clean summertime Arctic
}

\section{W. Richard Leaitch et al.}

Correspondence to: W. Richard Leaitch (richard.leaitch@canada.ca)

The copyright of individual parts of the supplement might differ from the CC-BY 3.0 licence. 


\section{S1. Instrument calibrations, evaluations}

The calibrations of the UCPC, SMS, UHSAS, CCN and FSSP100 were evaluated in the laboratory prior to integration on the aircraft and again with the instrumentation in the aircraft at Resolute Bay. The results of these evaluations are summarized below:

a) In the laboratory, a Gilibrator was used to determine the relevant flow rates were within $5 \%$ of their expected values for the UCPC, SMS and UHSAS. Particle sizing was evaluated against nearly monodisperse $80 \mathrm{~nm}$ and $200 \mathrm{~nm}$ polystyrene latex spheres (PSLs) as well as nearly monodisperse $50 \mathrm{~nm}$ and $100 \mathrm{~nm}$ particles of ammonium sulfate (AS); the latter were generated from the atomization of solution droplets that were dried and subsequently size-selected with a TSI 3081 Electrostatic Classifier. The classifier output was also sampled with a TSI 3034 SMPS for comparison, which sized to within $2 \%$ of the nominal settings of the PSLs and the 3081. The peak sizes measured with the SMS ranged from $2 \%$ to $10 \%$ higher than the nominal sizes. The UHSAS was evaluated only with the nearly monodisperse AS particles, and its peak sizes were found to be $6 \%-8 \%$ below the nominal sizes. The number concentrations of both the SMS and UHSAS were evaluated against number concentrations measured with a TSI 3772 $\mathrm{CPC}$, and the agreement was to within $7 \%$.

b) Particle transmission through the $\mathrm{CCN}$ low pressure inlet was assessed using two TSI 3772 CPCs: one placed before the inlet at approximately $995 \mathrm{hPa}$, and one after the inlet at reduced pressure of $650 \mathrm{hPa}$. The mean ratio of the reduced pressure CPC to the ambient pressure CPC for nearly monodisperse AS particles at several diameters ranging between $35 \mathrm{~nm}$ and $110 \mathrm{~nm}$ was 0.67 , which compares well with the expected reduction by a factor of approximately 0.65 . However, the ratio of the CPCs varied between 0.6 and 0.76 with the higher values at smaller particle sizes (Figure $\mathrm{S} 1$ ). The reason for the variation is unknown, but it suggests that the CCNC concentrations sampled through this lowpressure inlet may be artificially increased for particles $<70 \mathrm{~nm}$ and reduced for particles $>70 \mathrm{~nm}$ by up to $8 \%$.

c) The ratio of $\mathrm{CCNC}$ to $\mathrm{CPC}$ number concentrations input to the low-pressure inlet was found to be about 0.60 compared with the pressure ratio of 0.65 , suggesting some losses of smaller particles in the CCN instrument. Therefore, after correction to a standard atmosphere, the $\mathrm{CCNC}$ data are further multiplied by factor of 1.083. In-flight comparisons with the UCPC data indicated a lag of 16 seconds in the CCNC response due to the lower flow rate of the CCNC and the proximity of the low-pressure box to the intake point of the CCNC. Thus, all CCNC data have been shifted by 16 seconds.

d) Laboratory tests using ammonium sulfate particles and the reduced-pressure inlet ahead of the $\mathrm{CCN}$ instrument indicated the effective supersaturations were reduced from the nominal supersaturations tested $(0.2 \%, 0.6 \%, 0.8 \%$ and $1.0 \%)$ to 
values of $0.15 \%, 0.37 \%, 0.5 \%$ and $0.6 \%$ at an inlet pressure of $650 \mathrm{mb}$ (Figure S2). The nominal supersaturation was set to $1.0 \%$ for the study, thus representing an effective supersaturation of $0.6 \%$.

e) Size classified particles of ammonium sulfate were used to check sizing and number concentrations of the SMS, UHSAS and CCN in the aircraft in Resolute Bay. The number concentrations were evaluated against a TSI 3772 CPC and the UCPC (3787). Flow rates were also re-checked. The Resolute Bay in-aircraft tests confirmed the instruments were operating as characterized in the laboratory. The UCPC and the 3772 correlated with a $\mathrm{R}^{2}$ of $>0.99$ and a slope of 1.003 for generated particles larger than $20 \mathrm{~nm}$.

f) Figure S3 shows a comparison of the SMS and UHSAS in their overlap size range for the flight on July 19. The overall best comparison of the number concentrations is obtained by setting the SMS interval to $77 \mathrm{~nm}$ to $100 \mathrm{~nm}$, which is consistent with the opposite biases in the SMS and UHSAS sizing discussed above. The UHSAS and SMS may differ in their sizing due to differences between optical diameter (UHSAS) versus mobility diameter (SMS). Across the period shown in Figure 3, the averaged number concentrations for the SMS and UHSAS are $81.7 \mathrm{~cm}^{-3}$ and $73.3 \mathrm{~cm}^{-3}$, respectively. Considering this comparison and the calibrations, the uncertainties in the sizing of the SMS and the UHSAS are each estimated at $\pm 10 \%$, and the uncertainty in the number concentration measurement of each is also $\pm 10 \%$.

g) The CDNC derived from the FSSP-100 measurements are based on the number of counts per second divided by the sample volume, where the latter is derived from multiplication of the sample area by the true airspeed (TAS). The sample area is calculated from multiplication of the measured depth of field $(0.298 \mathrm{~cm})$ by the measured beam diameter $(0.02 \mathrm{~cm})$ and a theoretical factor of 0.62 . The 0.62 factor is derived based on geometric considerations of the transit time of a particle passing through the sample volume of the FSSP. The FSSP electronics sorts particles by transit time in order to exclude particles passing near the edge of the laser beam where the laser intensity is low and the particle size will be underestimated. The $\mathrm{CDNC}$ were calculated as follows:

$\mathrm{CDNC}=\mathrm{Counts}($ per sec. $) /(0.62 * 0.02 * 0.298 * \mathrm{TAS})$

where the units of TAS are $\mathrm{cm} \mathrm{s}^{-1}$. The CDNC have not been corrected for coincidence or probe dead time. These corrections are minor for the relatively low TAS (both mean and median values of $66 \mathrm{~m} \mathrm{~s}^{-1}$ ) and CDNC (maximum of the averaged values here is $273 \mathrm{~cm}^{-3}$ and the median of the averaged values is $58 \mathrm{~cm}^{-}$ ${ }^{3}$ ), but some of the higher CDNC may be biased slightly low. Corrections for flow around the aircraft were not taken into account because the effects of flow on the measurements are significantly less than the estimated probe measurement accuracies of the CDNC $( \pm 15 \%)$ for the airspeeds here Cober et al. [2001]. Sizing calibrations were done in the laboratory and repeated on the aircraft at 
Resolute Bay using $10 \mu \mathrm{m}$ diameter glass beads aspirated through the sample volume. The range covering 2-47 $\mu \mathrm{m}$ was used on all but two flights: the FSSP100 was operated on the 2-32 $\mu \mathrm{m}$ range during the flights conducted on July 8 and 10.

h) In-situ calibrations of the AL5002 CO monitor were conducted regularly in flight using a NIST traceable calibration gas with a known $\mathrm{CO}$ concentration at atmospheric level. Zero measurements are performed on a 15 to $30 \mathrm{~min}$ time interval during the measurement flights. The calibrations and zero measurements allow for corrections of instrument drift, thereby increasing the stability and accuracy of the instrument, and leading to an uncertainty of $\pm 2.3 \mathrm{ppbv}$ relative to the standard.

\section{References}

1) Cober, S.G., Isaac, G.A., Korolev, A.V. \& Strapp, W.: Assessing Cloud-Phase Conditions, J. Appl. Meteorol. 40, 1967-1983, 2001.

2) Mauritsen, T., J. Sedlar, M. Tjernström, C. Leck, M. Martin, M. Shupe, S. Sjogren, B. Sierau, P. O. G. Persson, I. M. Brooks, and E. Swietlicki (2011), An Arctic CCNlimited cloud-aerosol regime, Atmos. Chem. Phys., 11, 165-173, doi:10.5194/acp-11165-2011. 


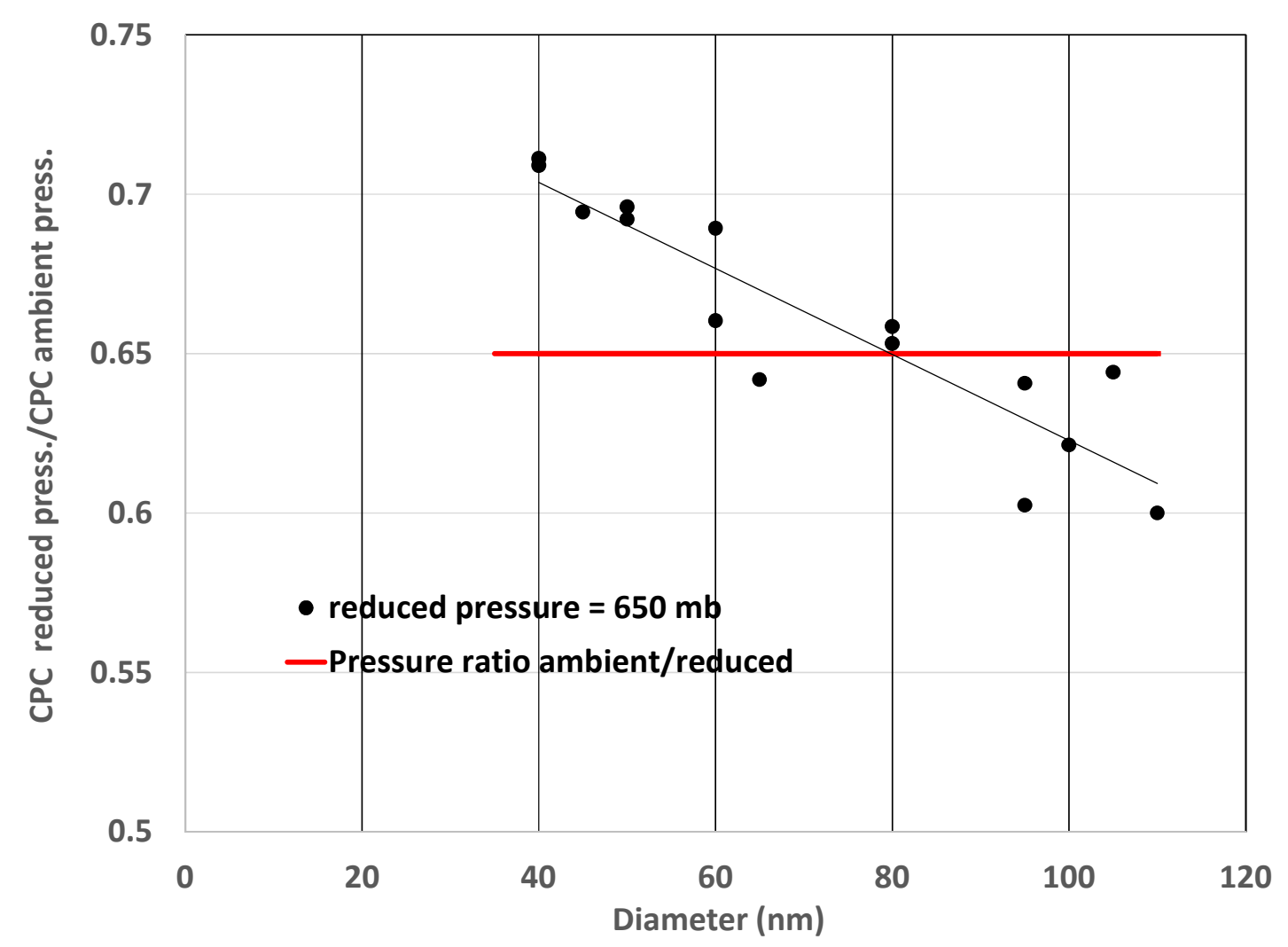

Figure S1. Plot of 3772 CPC operating at reduced pressure downstream of the DMT lowpressure inlet used in front of the CCNC relative to the $3772 \mathrm{CPC}$ operating at ambient pressure. The red line show the ratio based on the pressure differential between the lowpressure inlet and ambient. 


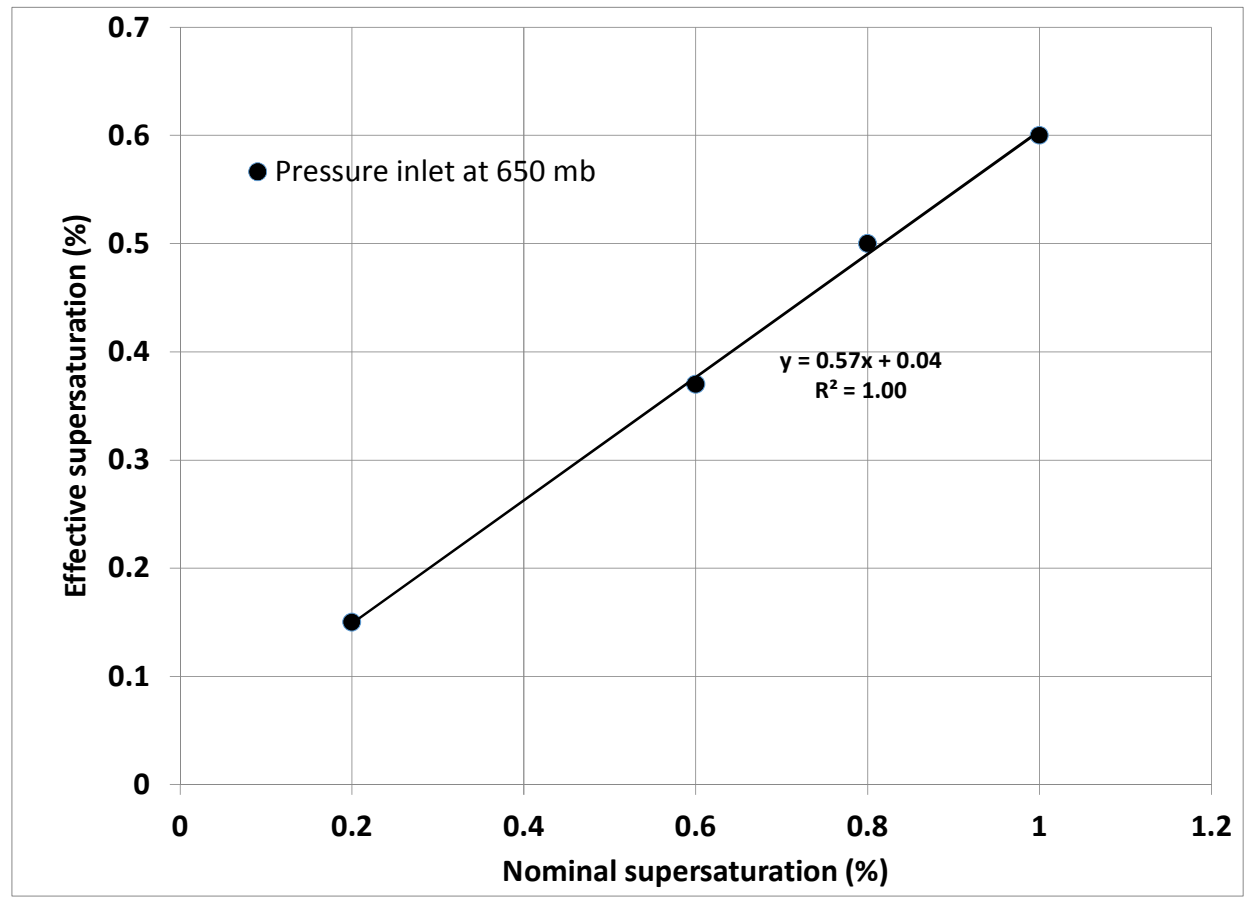

Figure S2. Plot of the effective supersaturation of the CCNC instrument against the nominal supersaturation setting for the CCNC operating downstream of the low-pressure inlet set at $650 \mathrm{mb}$.Type or paste caption here. 


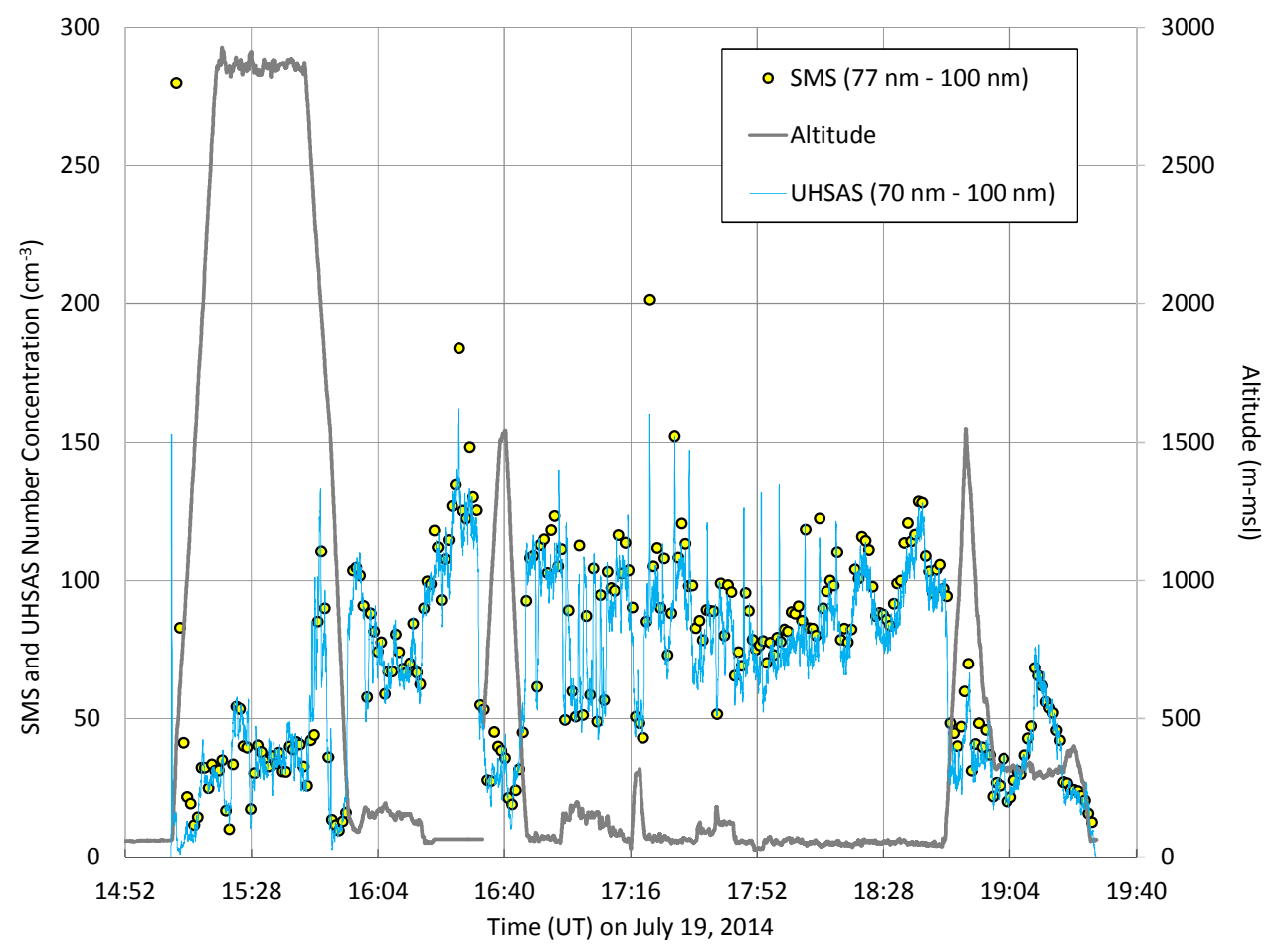

Figure S3. Comparison of 1-minute averaged SMS and 10-second averaged UHSAS data for the intervals of 77-100 nm and 70-100 nm, respectively. Example is from July 19 . 


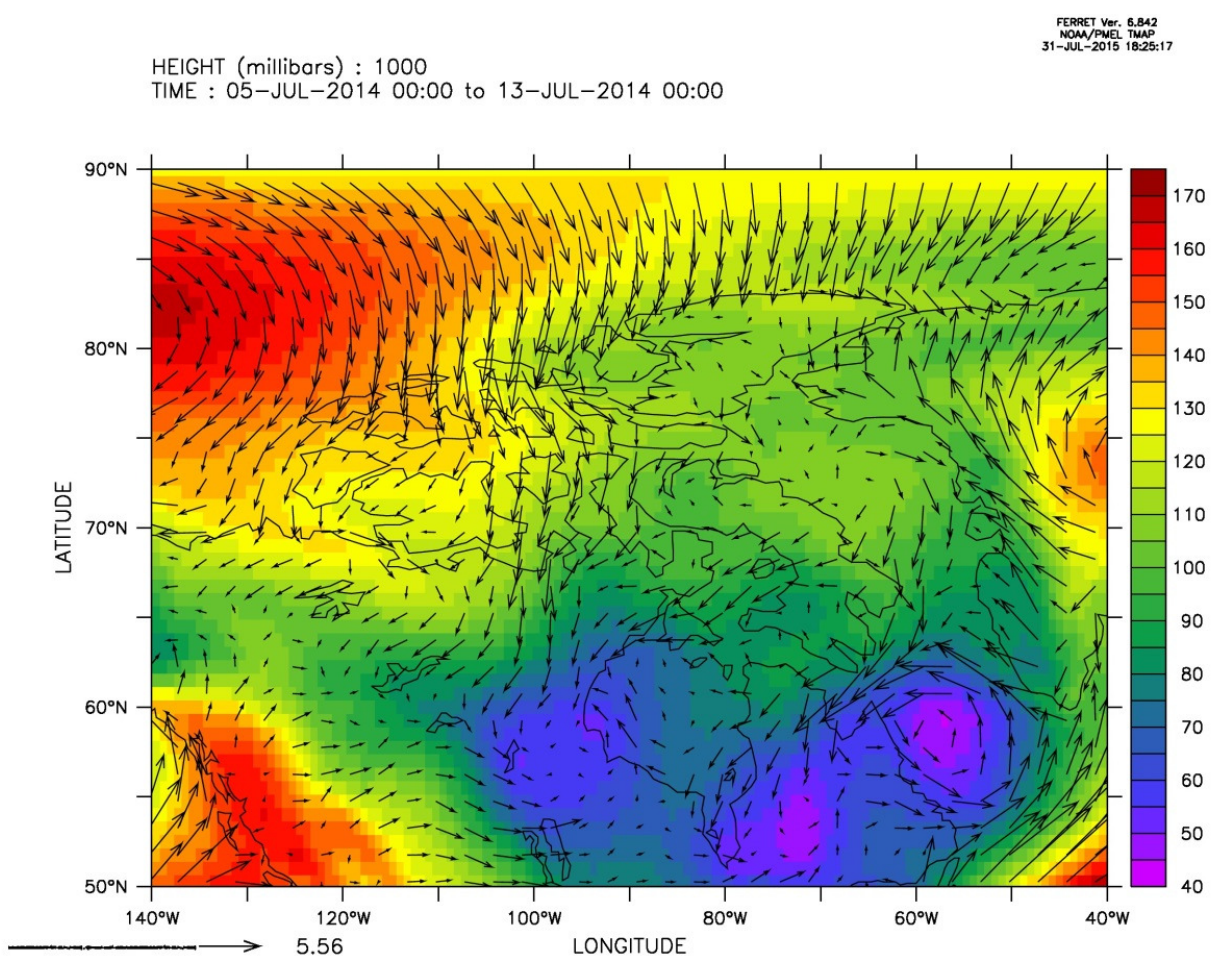

dPOT[L=5:12@AVE,K=10,D=netcdf - atls01-a562cefde8a29a7288fa0b8b7f9413f7-69ufhw]/9.81

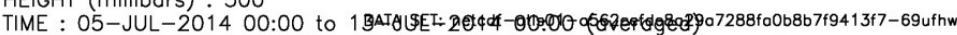

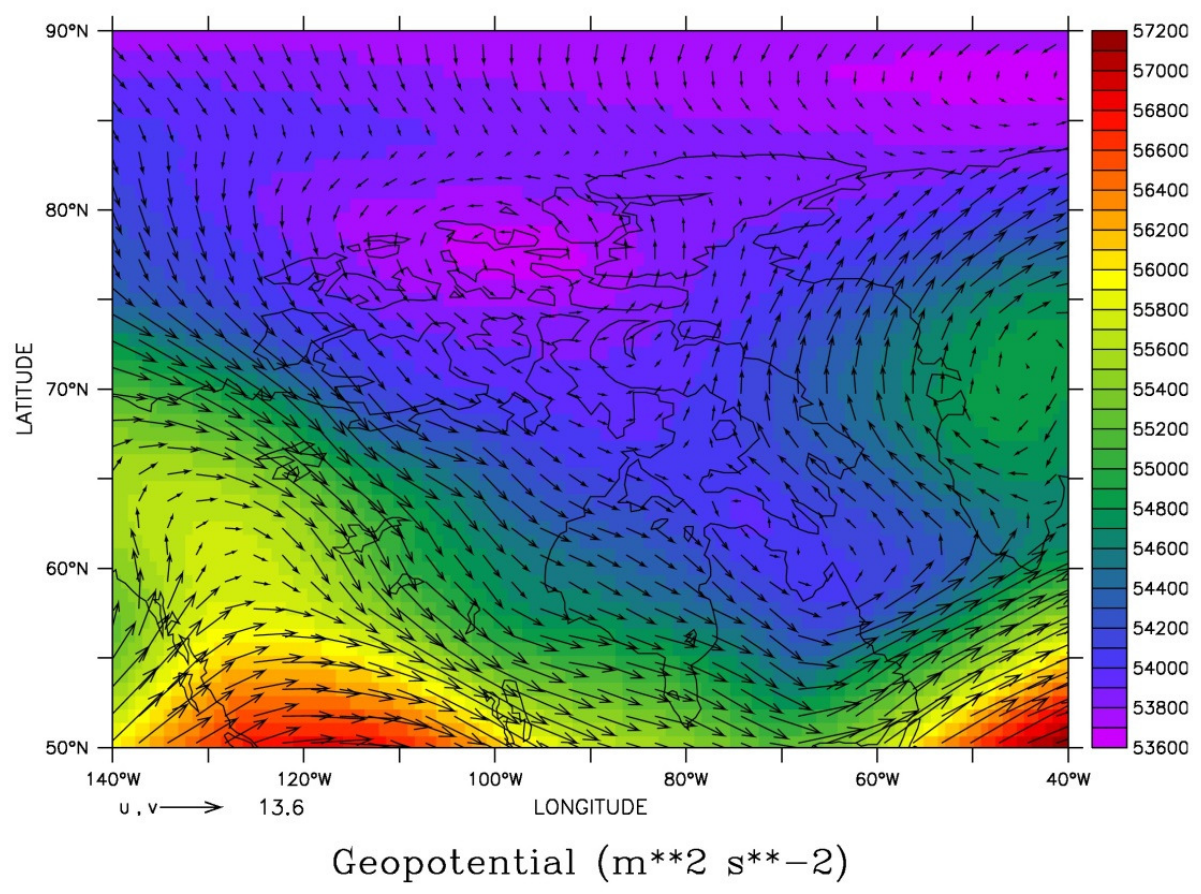

Figure S4. Surface and $500 \mathrm{hPa}$ geopotential height for period 1. 
HEIGHT (millibars) : 1000

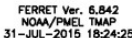

TIME : 14-JUL-2014 00:00 to 20-JUL-2014 00:00

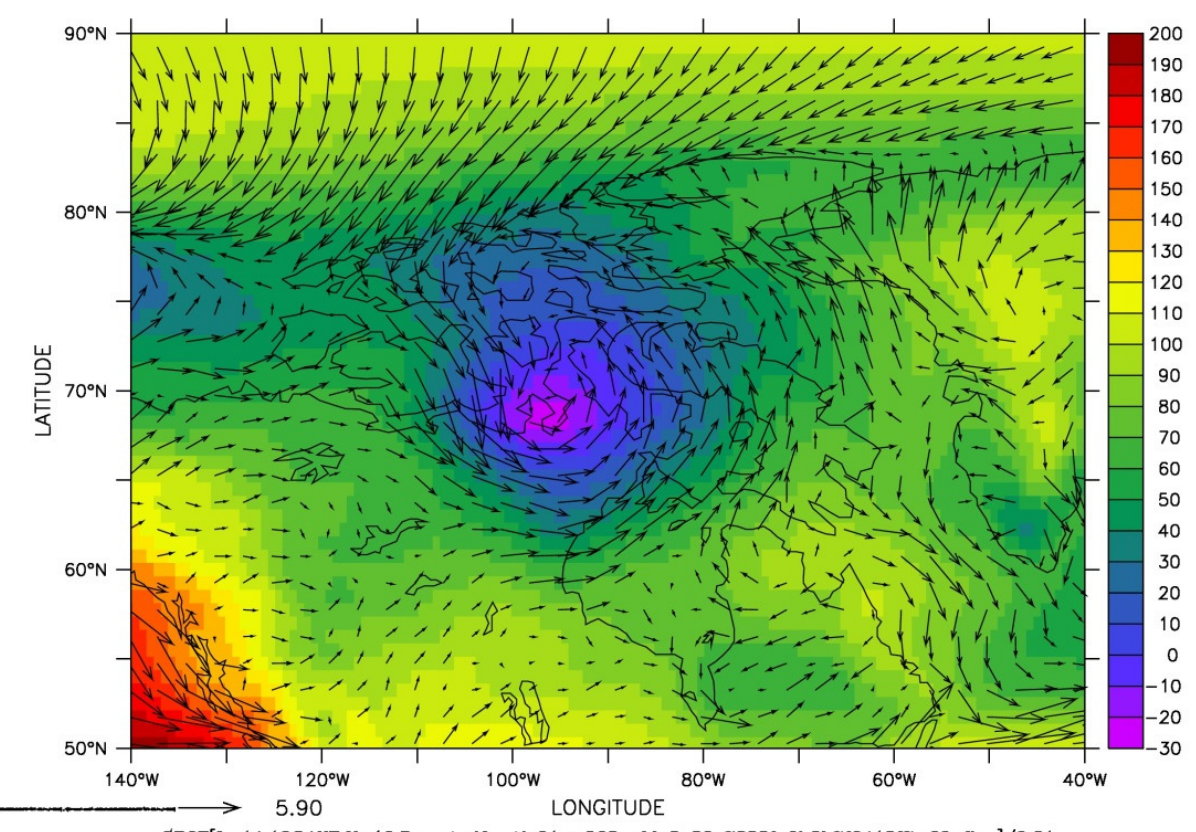

GPOT[L=14:19@AVE,K=10,D=netcdf - atls01 - a562cefde8a29a7288fa0b8b7f94 13f7-69ufhw] $] / 9.81$

HEIGHT (millibars) : 500

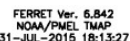

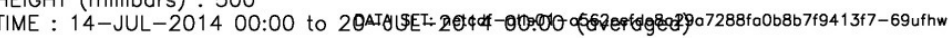

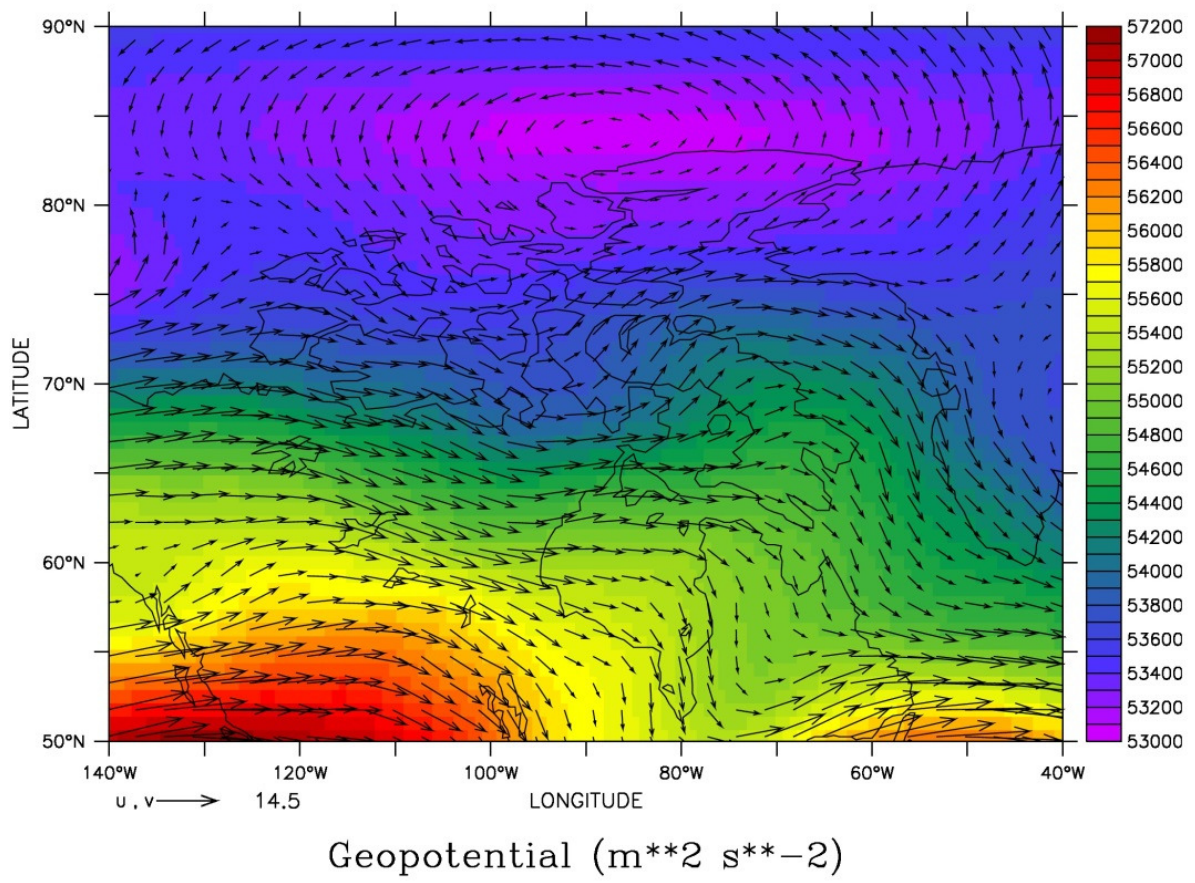

Figure S5. Surface and $500 \mathrm{hPa}$ geopotential height for period 2. 

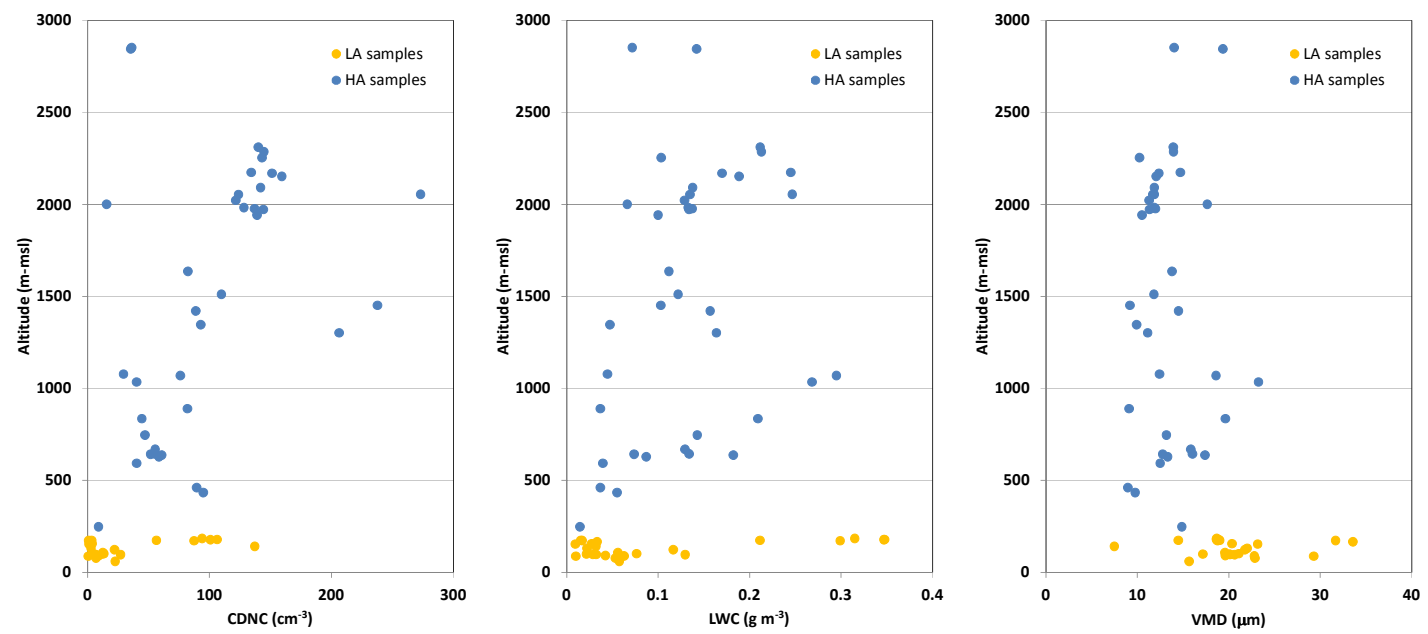

Figure S6. Plots of CDNC, LWC and VMD as a function of altitude for the LA and HA samples. 


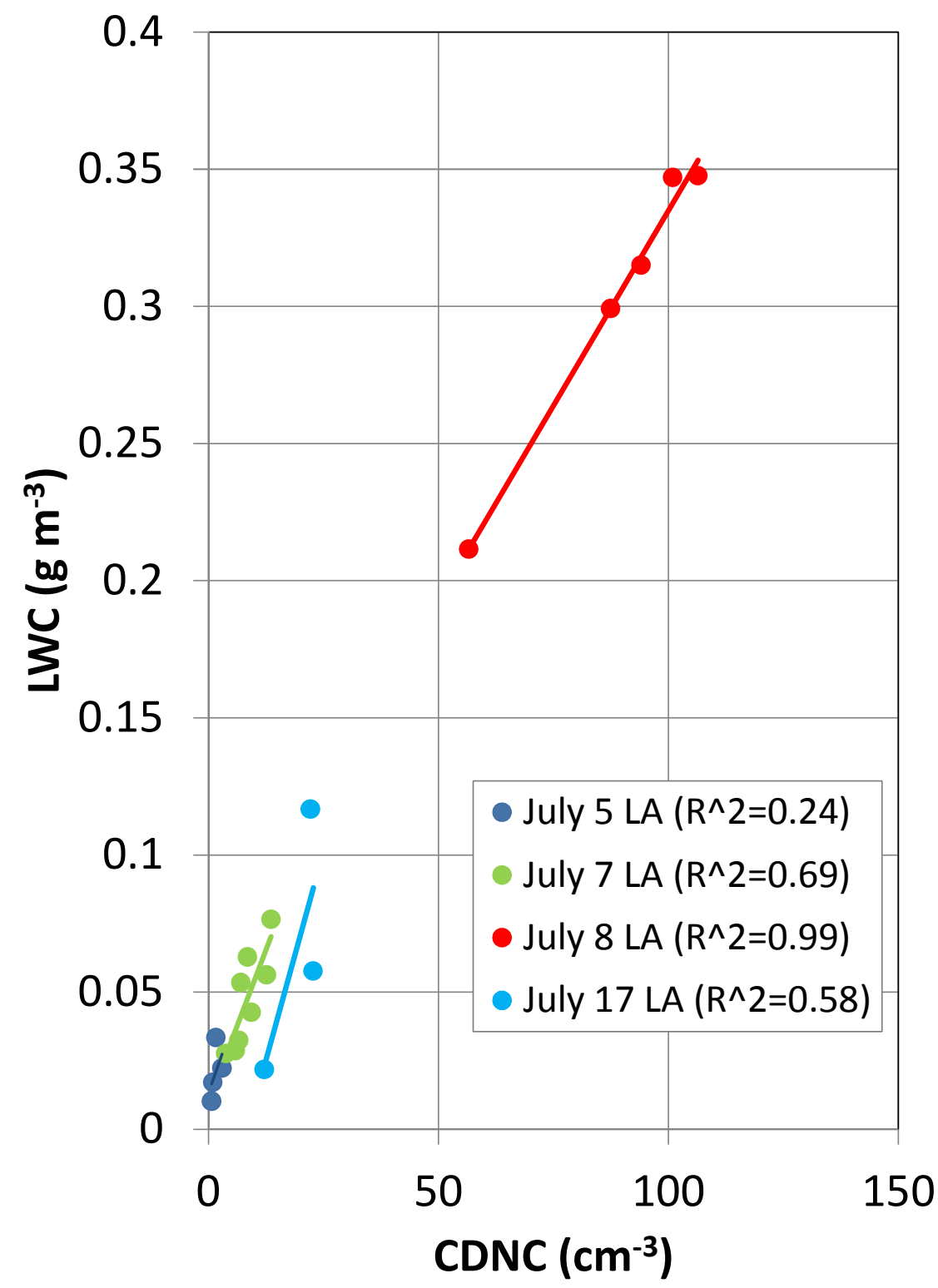

Figure S7. Plot of LWC versus CDNC for the specific LA cases of July 5, 7, 8 and 17. Linear regressions for each set of samples are also plotted, and the coefficients of determination are given in the legends. The slopes are significant at a $95 \%$ confidence level within $\pm 30 \%$ for July 7 and within $60 \%$ for July 8 . The slopes in the July 5 and 17 cases are not significant at a $95 \%$ confidence level. 


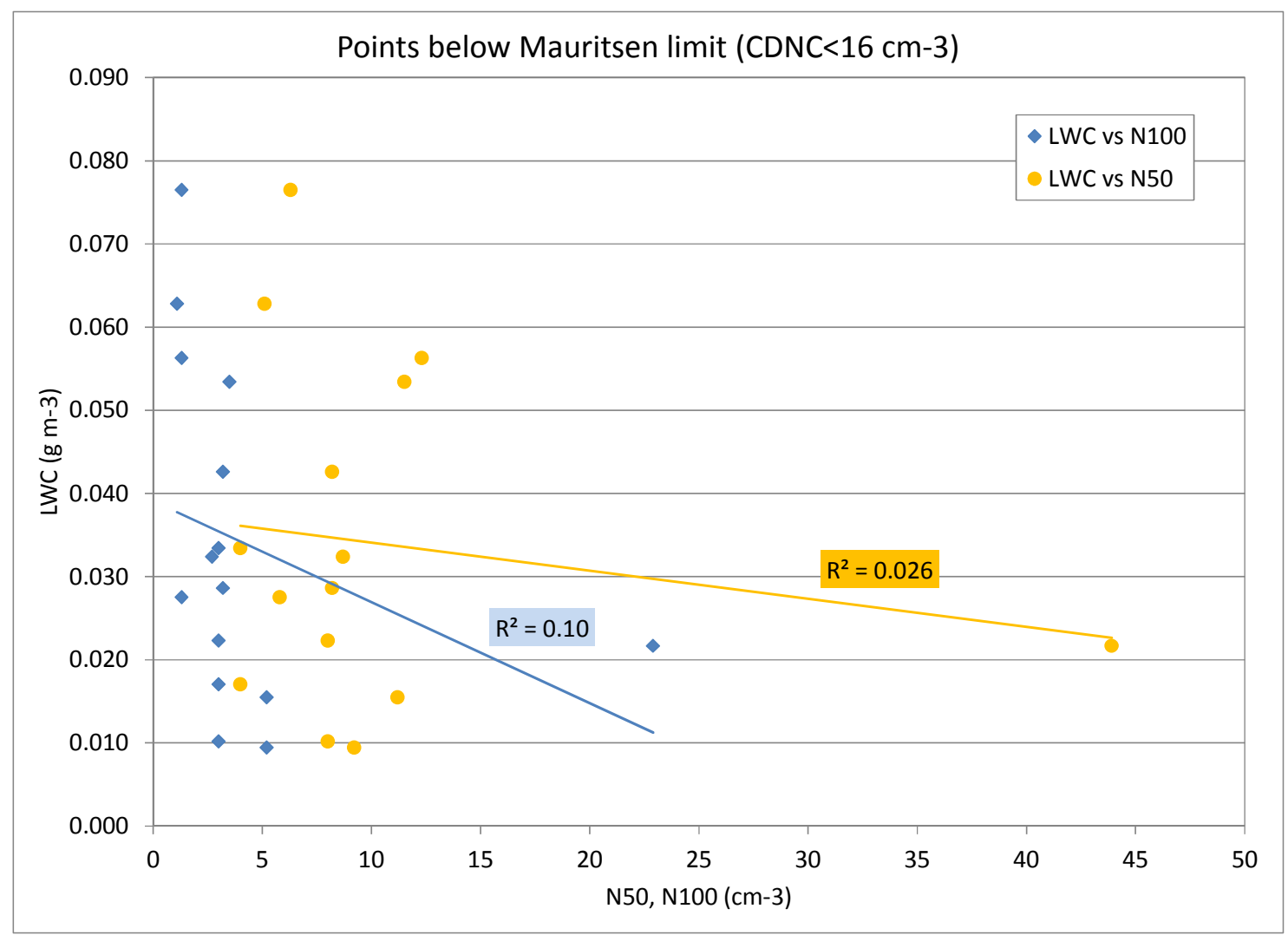

Figure S8. - Liquid water content (LWC) versus aerosol particle number concentrations $>50 \mathrm{~nm}(\mathrm{~N} 50)$ and $>100 \mathrm{~nm}(\mathrm{~N} 100)$ for the subset of the 62 points that fall below the CCN (or CDNC) limit discussed by Mauritsen et al. [2011]. The limit is estimated for these measurements at $16 \mathrm{~cm}^{-3}$. 
Data Table

\begin{tabular}{|c|c|c|c|c|c|c|c|c|c|c|c|c|c|c|}
\hline $\begin{array}{l}\text { Flight } \\
\#\end{array}$ & $\begin{array}{l}\text { CDNC } \\
\text { at } \\
\text { STP }\end{array}$ & CDNC & LWC & VMD & Altitude_m & TAS_m/s & Temp_c & $\begin{array}{l}\text { Number } \\
\text { of } \\
\text { seconds } \\
\text { in Ave }\end{array}$ & $\begin{array}{l}\text { Cloud } \\
\text { depth } \\
\text { (m) }\end{array}$ & LWP & $\begin{array}{l}\text { N100 } \\
\text { (pre- } \\
\text { cloud) }\end{array}$ & $\begin{array}{l}\text { N50 } \\
\text { (pre- } \\
\text { cloud) }\end{array}$ & $\begin{array}{l}\text { CCNC } \\
\text { at } \\
0.6 \% \\
\text { (pre- } \\
\text { cloud) }\end{array}$ & $\begin{array}{l}\text { CO } \\
\text { (ppbv) }\end{array}$ \\
\hline \multirow[t]{4}{*}{6} & 2.8 & 3.0 & 0.02 & 22.0 & 130.4 & 67.3 & -2.6 & 215.00 & NA & & 3.0 & 8.0 & 5.0 & 80.0 \\
\hline & 0.7 & 0.7 & 0.01 & 29.3 & 87.7 & 65.5 & -1.7 & 43.00 & NA & & 3.0 & 8.0 & 5.0 & 82.5 \\
\hline & 1.6 & 1.7 & 0.03 & 33.6 & 166.3 & 69.3 & -2.6 & 13.00 & NA & & 3.0 & 4.0 & 2.0 & 79.6 \\
\hline & 0.9 & 1.0 & 0.02 & 31.7 & 173.1 & 67.2 & -2.5 & 54.00 & NA & & 3.0 & 4.0 & 2.0 & 79.8 \\
\hline \multirow[t]{21}{*}{7} & 162.2 & 137.1 & 0.14 & 12.0 & 1976.8 & 71.3 & -4.0 & 66.00 & 172 & 23.6 & 47.2 & 148.2 & & 77.5 \\
\hline & 170.7 & 144.3 & 0.13 & 11.3 & 1972.4 & 63.1 & -4.4 & 103.00 & 201 & 26.9 & 47.2 & 135.2 & & 77.8 \\
\hline & 164.0 & 139.2 & 0.10 & 10.5 & 1942.3 & 73.4 & -4.2 & 95.00 & 161 & 16.1 & 47.0 & 135.0 & & 78.1 \\
\hline & 151.9 & 128.4 & 0.13 & 11.9 & 1982.9 & 66.3 & -4.6 & 85.00 & 233 & 31.0 & 47.0 & 135.0 & & 77.9 \\
\hline & 144.6 & 121.6 & 0.13 & 11.3 & 2022.0 & 69.1 & -4.9 & 87.00 & 149 & 19.2 & 55.0 & 143.0 & & 77.7 \\
\hline & 147.8 & 123.9 & 0.13 & 11.7 & 2053.7 & 65.1 & -4.9 & 95.00 & 214 & 28.9 & 58.0 & 150.0 & & 77.0 \\
\hline & 169.6 & 142.0 & 0.14 & 11.9 & 2091.6 & 68.7 & -5.3 & 91.00 & 196 & 27.0 & 40.0 & 132.0 & & 77.8 \\
\hline & 161.9 & 134.4 & 0.25 & 14.7 & 2173.7 & 65.9 & -5.8 & 148.00 & 309 & 75.7 & 50.0 & 134.0 & & \\
\hline & 182.2 & 151.4 & 0.17 & 12.4 & 2169.2 & 70.8 & -6.1 & 142.00 & 295 & 50.2 & 50.0 & 138.0 & & \\
\hline & 8.1 & 8.5 & 0.06 & 22.8 & 87.8 & 65.6 & -0.3 & 138.00 & NA & & 1.1 & 5.1 & & 80.8 \\
\hline & 8.9 & 9.3 & 0.04 & 19.6 & 91.0 & 64.0 & -0.2 & 95.00 & NA & & 3.2 & 8.2 & & 80.6 \\
\hline & 5.6 & 5.9 & 0.03 & 20.1 & 97.7 & 64.2 & -0.2 & 36.00 & NA & & 3.2 & 8.2 & & 80.4 \\
\hline & 6.3 & 6.7 & 0.03 & 20.1 & 96.8 & 64.6 & -0.2 & 145.00 & NA & & 2.7 & 8.7 & & 80.5 \\
\hline & 13.0 & 13.6 & 0.08 & 21.1 & 101.1 & 63.2 & -0.3 & 309.00 & NA & & 1.3 & 6.3 & & 80.7 \\
\hline & 3.6 & 3.8 & 0.03 & 20.4 & 155.7 & 61.7 & -0.2 & 176.00 & NA & & 1.3 & 5.8 & & 79.8 \\
\hline & 12.1 & 12.7 & 0.06 & 19.6 & 107.1 & 68.7 & -0.1 & 74.00 & NA & & 1.3 & 12.3 & & 80.2 \\
\hline & 191.8 & 159.5 & 0.19 & 12.1 & 2152.6 & 70.6 & -6.0 & 132.00 & 328 & 61.8 & 59.0 & 146.0 & & 78.8 \\
\hline & 6.7 & 7.1 & 0.05 & 22.9 & 76.9 & 62.5 & -0.4 & 174.00 & NA & & 3.5 & 11.5 & & 80.4 \\
\hline & 198.8 & 163.5 & 0.12 & 10.9 & 2265.3 & 70.3 & -6.5 & 67.00 & 172 & 20.5 & 67.0 & 155.0 & 120.0 & 78.4 \\
\hline & 171.4 & 140.2 & 0.21 & 13.9 & 2311.3 & 69.1 & -6.8 & 211.0 & NA & & 67.0 & 144.0 & 120.0 & 78.3 \\
\hline & 176.2 & 144.7 & 0.21 & 14.0 & 2286.1 & 68.8 & -6.8 & 146.0 & NA & & 67.0 & 144.0 & 120.0 & 78.8 \\
\hline \multirow[t]{5}{*}{8} & 84.7 & 87.5 & 0.30 & 18.8 & 171.6 & 64.3 & 2.0 & 60.0 & 58 & 17.4 & 73.0 & 319.0 & 168.0 & 80.9 \\
\hline & 54.9 & 56.6 & 0.21 & 19.0 & 173.5 & 63.5 & 2.1 & 47.0 & 58 & 12.3 & 73.0 & 319.0 & 168.0 & 81.0 \\
\hline & 103.2 & 106.4 & 0.35 & 18.7 & 178.1 & 62.1 & 2.1 & 50.0 & 70 & 24.3 & 73.0 & 319.0 & 168.0 & 80.6 \\
\hline & 91.4 & 94.1 & 0.32 & 18.7 & 183.7 & 62.3 & 2.2 & 64.0 & 80 & 25.2 & 73.0 & 319.0 & 168.0 & 80.5 \\
\hline & 98.1 & 101.0 & 0.35 & 18.9 & 177.5 & 65.3 & 2.3 & 54.0 & 64 & 22.2 & 73.0 & 319.0 & 168.0 & 80.2 \\
\hline \multirow[t]{5}{*}{9} & 3.3 & 3.5 & 0.02 & 14.5 & 173.4 & 63.3 & 0.9 & 1000.0 & NA & & 5.2 & 11.2 & 5.7 & 77.6 \\
\hline & 1.2 & 1.2 & 0.01 & 23.2 & 153.6 & 65.1 & 0.6 & 95.0 & NA & & 5.2 & 9.2 & 6.0 & 77.9 \\
\hline & 94.9 & 94.9 & 0.06 & 9.8 & 434.1 & 70.8 & 2.2 & 11.0 & 29 & 1.6 & 31.0 & 109.0 & 88.0 & 76.0 \\
\hline & 89.5 & 89.6 & 0.04 & 9.0 & 460.5 & 65.6 & 1.2 & 23.0 & 35 & 1.3 & 21.0 & 99.0 & 88.0 & 77.0 \\
\hline & 103.5 & 93.0 & 0.05 & 9.9 & 1345.8 & 67.7 & 0.6 & 16.0 & NA & & 75.0 & 195.0 & 136.0 & 75.8 \\
\hline \multirow[t]{10}{*}{11} & 50.3 & 47.2 & 0.14 & 13.2 & 746.5 & 66.4 & 1.5 & 58.0 & 177 & 25.3 & 24.2 & 69.2 & 45.0 & 82.0 \\
\hline & 54.8 & 51.8 & 0.07 & 12.8 & 642.0 & 71.0 & 2.3 & 19.0 & 68 & 5.0 & 30.5 & 86.5 & 45.0 & 83.2 \\
\hline & 22.4 & 22.8 & 0.06 & 15.7 & 59.6 & 71.6 & 2.3 & 157.0 & 50 & 2.9 & 10.3 & 23.3 & 17.0 & 79.8 \\
\hline & 9.1 & 9.1 & 0.01 & 14.9 & 247.8 & 66.7 & 2.3 & 37.0 & 21 & 0.3 & 11.4 & 42.4 & 43.0 & 82.8 \\
\hline & 22.0 & 22.2 & 0.12 & 21.8 & 122.9 & 66.3 & 2.5 & 70.0 & 110 & 12.8 & 22.0 & 49.0 & 28.0 & 80.7 \\
\hline & 12.1 & 12.2 & 0.02 & 17.2 & 98.9 & 62.3 & 3.0 & 44.0 & 40 & 0.9 & 22.9 & 43.9 & 26.0 & \\
\hline & 42.7 & 40.5 & 0.04 & 12.5 & 592.8 & 70.4 & 2.5 & 18.0 & 46 & 1.8 & 22.1 & 65.1 & 48.0 & 82.1 \\
\hline & 58.9 & 55.6 & 0.13 & 15.9 & 668.7 & 71.1 & 1.6 & 46.0 & 152 & 19.7 & 30.2 & 63.2 & 35.0 & 84.9 \\
\hline & 58.4 & 55.3 & 0.13 & 16.1 & 643.5 & 66.4 & 1.4 & 48.0 & 141 & 18.9 & 29.8 & 60.8 & 38.0 & 85.6 \\
\hline & 61.9 & 58.6 & 0.09 & 13.3 & 628.6 & 70.1 & 2.2 & 44.0 & 135 & 11.8 & 25.4 & 68.4 & 59.0 & 82.6 \\
\hline \multirow[t]{7}{*}{12} & 342.8 & 273.3 & 0.25 & 11.9 & 2054.5 & 81.2 & -1.8 & 48.0 & 160 & 39.5 & 461.0 & 594.0 & 350.0 & \\
\hline & 98.7 & 82.4 & 0.11 & 13.8 & 1636.2 & 80.4 & -1.0 & 67.0 & 160 & 17.9 & 297.0 & 334.0 & 210.0 & \\
\hline & 129.9 & 109.9 & 0.12 & 11.8 & 1511.3 & 74.9 & 1.7 & 17.0 & 12 & 1.5 & 184.0 & 232.0 & 175.0 & 102.9 \\
\hline & 103.7 & 88.8 & 0.16 & 14.5 & 1420.6 & 70.5 & 1.7 & 49.0 & 197 & 30.9 & 68.5 & 93.5 & 81.0 & 102.2 \\
\hline & 138.3 & 137.2 & 0.03 & 7.5 & 141.0 & 68.7 & 4.3 & 20.0 & NA & & 149.0 & 315.0 & 230.0 & 89.6 \\
\hline & 239.1 & 206.5 & 0.16 & 11.1 & 1301.9 & 67.8 & 2.6 & 39.0 & 204 & 33.4 & 197.4 & 269.4 & 175.0 & 105.9 \\
\hline & 275.5 & 237.9 & 0.10 & 9.2 & 1451.3 & 66.5 & 1.7 & 15.0 & 99 & 10.2 & 221.0 & 334.0 & 221.0 & 112.6 \\
\hline \multirow[t]{9}{*}{13} & 19.5 & 15.8 & 0.07 & 17.7 & 2000.9 & 76.6 & -2.1 & 47.0 & 173 & 11.5 & 19.5 & 31.5 & 19.5 & 94.9 \\
\hline & 44.8 & 40.3 & 0.27 & 23.3 & 1034.5 & 67.5 & 1.7 & 85.0 & 275 & 73.8 & 24.0 & 44.0 & 24.0 & 87.6 \\
\hline & 48.5 & 44.7 & 0.21 & 19.7 & 835.0 & 65.7 & 2.4 & 26.0 & 89 & 18.6 & 32.0 & 52.0 & 32.0 & 86.9 \\
\hline & 64.9 & 61.0 & 0.18 & 17.4 & 637.1 & 65.9 & 3.3 & 85.0 & 284 & 51.8 & 34.0 & 66.0 & 35.0 & 86.6 \\
\hline & 90.1 & 82.0 & 0.04 & 9.1 & 889.4 & 71.2 & 3.5 & 71.0 & 39 & 1.4 & 65.4 & 105.4 & 56.0 & 88.3 \\
\hline & 85.1 & 76.2 & 0.30 & 18.6 & 1069.2 & 70.7 & 2.3 & 132.0 & 359 & 105.9 & 71.1 & 134.1 & 65.0 & 88.7 \\
\hline & 49.3 & 36.3 & 0.07 & 14.0 & 2852.7 & 72.9 & -6.1 & 42.0 & NA & & 46.3 & 78.3 & 42.0 & \\
\hline & 48.2 & 35.5 & 0.14 & 19.4 & 2845.0 & 73.2 & -6.1 & 34.0 & NA & & 44.0 & 71.0 & 42.0 & 108.6 \\
\hline & 33.1 & 29.6 & 0.04 & 12.4 & 1077.4 & 68.8 & 2.3 & 41.0 & 120 & 5.4 & 20.0 & 28.0 & 15.0 & 88.1 \\
\hline 15 & 26.7 & 27.3 & 0.13 & 20.7 & 96.0 & 62.8 & 0.9 & 80.0 & 29 & 3.8 & 25.3 & 40.3 & 21.0 & 81.7 \\
\hline
\end{tabular}


